\title{
Surface deformation of active volcanic areas retrieved with the SBAS-DInSAR technique: an overview
}

\author{
Antonio Pepe $\left({ }^{1}\right)$, Mariarosaria Manzo $\left({ }^{1}\right)\left({ }^{2}\right)$, Francesco Casu $\left({ }^{1}\right)\left({ }^{3}\right)$, Giuseppe Solaro $\left({ }^{1}\right)$, \\ Pietro Tizzani $\left({ }^{1}\right)$, Giovanni Zeni $\left({ }^{1}\right)\left({ }^{2}\right)$ and Susi Pepe $\left({ }^{4}\right)$ \\ (') Istituto per il Rilevamento Elettromagnetico dell'Ambiente, CNR, Napoli, Italy \\ ${ }^{(2)}$ Dipartimento di Ingegneria e Fisica dell'Ambiente, Università degli Studi della Basilicata, Potenza, Italy \\ $\left(^{3}\right)$ Dipartimento di Ingegneria Elettrica ed Elettronica, Università degli Studi di Cagliari, Italy \\ $\left(^{4}\right)$ Istituto Nazionale di Geofisica e Vulcanologia, Osservatorio Vesuviano, Napoli, Italy
}

\begin{abstract}
This paper presents a comprehensive overview of the surface deformation retrieval capability of the Differential Synthetic Aperture Radar Interferometry (DInSAR) algorithm, referred to as Small BAseline Subset (SBAS) technique, in the context of active volcanic areas. In particular, after a brief description of the algorithm some experiments relevant to three selected case-study areas are presented. First, we concentrate on the application of the SBAS algorithm to a single-orbit scenario, thus considering a set of SAR data composed by images acquired on descending orbits by the European Remote Sensing (ERS) radar sensors and relevant to the Long Valley caldera (eastern California) area. Subsequently, we address the capability of the SBAS technique in a multipleorbit context by referring to Mt. Etna volcano (southern Italy) test site, with respect to which two different ERS data set, composed by images acquired both on ascending and descending orbits, are available. Finally, we take advantage of the capability of the algorithm to work in a multi-platform scenario by jointly exploiting two different sets of SAR images collected by the ERS and the Environment Satellite (ENVISAT) radar sensors in the Campi Flegrei caldera (southern Italy) area. The presented results demonstrate the effectiveness of the algorithm to investigate the deformation field in active volcanic areas and the potential of the DInSAR methodologies within routine surveillance scenario.
\end{abstract}

Key words Ground deformation - Differential Interferometry

\section{Introduction}

Differential Synthetic Aperture Radar Interferometry (DInSAR) is a microwave remote sensing technique that allows us to investigate surface deformation phenomena with a cen-

Mailing address: Dr. Antonio Pepe, Istituto per il Rilevamento Elettromagnetico dell'Ambiente, CNR, Via Diocleziano 328, I-80124 Napoli, Italy; e-mail: pepe.a@irea.cnr.it timeter to millimeter accuracy with a large spatial coverage capacity (Gabriel et al., 1989). In particular, the DInSAR technique exploits the phase difference (interferogram) between two SAR acquisitions, relevant to temporally separated observations of the same investigated area to provide a measure of the ground deformation projection along the radar Line Of Sight (LOS).

First applied to investigate single deformation events (Massonet et al., 1993; Peltzer and Rosen, 1995), the DInSAR methodology has been more recently exploited to analyze the temporal evolution of the detected displacements via the generation of deformation time series. For this purpose, the information available from each interferometric SAR data pair 
must be properly related to that included in the other ones, by generating and inverting an appropriate sequence of DInSAR interferograms. In this context, several approaches, aimed at following the temporal evolution of the detected displacements, have already been presented, see Ferretti et al. (2000), Berardino et al. (2002), Mora et al. (2003), Usai (2003), Werner et al. (2003), Hooper et al. (2004), and Crosetto et al. (2005).

In this work, we concentrate on the technique referred to as Small BAseline Subset (SBAS) approach proposed by Berardino et al. (2002) that allows us to produce both deformation time series and mean deformation velocity maps, by analyzing SAR data pairs characterized by small spatial and temporal separation between the acquisition orbits (baseline), whose capability to detect and investigate deformation phenomena has already been shown in different applications (Lanari et al., 2004a; Lundgren et al., 2004; Borgia et al., 2005; Manzo et al., 2006). In particular, we focus on the basic SBAS technique which exploits average (multilook) interferograms (Rosen et al., 2000), thus allowing us to reduce the amount of the processed data and simplifying the analysis of extended areas (typically of about $100 \times 100 \mathrm{~km}$ ). This possibility permits us to emphasize the relationship between local deformation patterns, i.e., displacements due to a volcanic source and regional patterns associated with tectonic processes.

The key idea of the work is to provide first a brief description of the basic rationale of the SBAS algorithm and, subsequently, to discuss the results achieved by applying this approach to the European Remote Sensing (ERS) and Environment Satellite (ENVISAT) SAR data in three selected case studies relevant to active volcanoes areas.

First of all, the surface deformation retrieval capability of the SBAS algorithm in a single-orbit scenario is explored. More specifically, we processed a set of SAR images of the Long Valley caldera (eastern California) area, acquired on descending orbits in the 1992-2000 time interval, and we produced the «standard» SBASDInSAR products, such as deformation time series and mean deformation velocity maps in the radar LOS.
The second selected case study refers to Mt. Etna volcano (Southern Italy) area and allows us to show how the SBAS algorithm works in a multiple-orbit context, where two different SAR data sets, collected by ascending and descending orbits, are combined to make an evaluation of the vertical and the east-west horizontal component of the deformation pattern. More specifically, two sets of SAR images, spanning the 19922001 time interval and collected both on ascending and descending orbits, have been exploited.

Finally, the capability of the SBAS algorithm in a multi-platform scenario, where data produced by different radar sensors are properly combined to produce deformation time series, has been addressed. This is the case of the Campi Flegrei caldera (southern Italy) area, with respect to which two different descending SAR data sets are available, where the former is composed by ERS-1/2 images acquired in the 1992-2005 time interval and the latter by those acquired since 2002 by the new ENVISAT-IS2 radar sensor, respectively.

A section dedicated to the main conclusions of the work and future developments is also provided.

\section{Basic rationale of the SBAS algorithm}

This section presents the rationale of the SBAS technique (Berardino et al., 2002) that was originally developed to detect deformation patterns and to analyze their temporal evolution by using multilook DInSAR interferograms (Rosen et al., 2000) with relatively low resolution that is typically of the order of $100 \times 100 \mathrm{~m}$.

In particular, the SBAS algorithm, discussed in detail in Berardino et al. (2002), relies on the use of a large number of SAR acquisitions and implements an easy combination of the multilook DInSAR interferograms computed from these data, finally leading to the generation of mean deformation velocity maps and corresponding time series.

In order to summarize the main aspects of the SBAS procedure, we will use the same notation of Berardino et al. (2002) and we will assume the availability of a set of $N+1$ SAR images relative to the same area, acquired at the 
ordered times $\left(t_{0}, \ldots, t_{N}\right)$ and co-registered with respect to a single image (referred to as master), in order to have a common reference grid.

The first step of the SBAS technique is represented by the generation of a number, say $M$, of differential interferograms, each of these representing the phase difference between SAR image pairs after the removal of the topographic phase contribution (Gabriel et al., 1989). A key issue of the SBAS procedure is the appropriate selection of a useful interferometric data pair distribution, in such a way as to mitigate the noise effects, referred to as decorrelation phenomena (Zebker and Villasenor, 1992), that decrease the signal-to-noise ratio (SNR) of the interferometric phase. In particular, the above mentioned SAR image pair selection is based on the introduction of constraints on the maximum allowed spatial and temporal baselines.

Note also that a retrieval step (usually referred to as phase unwrapping) of the original (unwrapped) phase from the modulo- $2 \pi$ restricted (wrapped) signal directly computed from the generated interferograms is carried out. This operation is implemented, in our case, via the minimum cost flow phase unwrapping algorithm proposed by Costantini and Rosen (1999), followed by a region growing procedure that improves the algorithm performance in areas with low coherence (i.e. low SNR) values. Moreover, the interferograms are calibrated with respect to a single pixel (often referred to as reference SAR pixel) located in an area that can be assumed stable or, at least, with a known deformation behavior.

Let us now refer to a generic pixel of azimuth and range coordinates $(x, r)$; the expression of the generic $k$-th unwrapped interferogram computed from the SAR acquisitions at times $t_{B}$ and $t_{A}$, according to Berardino et al. (2002), will be the following:

$$
\begin{aligned}
& \delta \varphi_{k}(x, r)=\varphi\left(t_{B}, x, r\right)-\varphi\left(t_{A}, x, r\right) \approx \\
& \frac{4 \pi}{\lambda} d\left(t_{B}, x, r\right)-d\left(t_{A}, x, r\right)+\Delta \varphi_{k}^{\text {topo }}(x, r)+ \\
& +\Delta \varphi_{k}^{a t m}\left(t_{B}, t_{A}, x, r\right)+\Delta n_{k}(x, r)
\end{aligned}
$$

wherein $\mathrm{k} \in(1, \ldots, \mathrm{M}), \varphi\left(t_{B}, x, r\right)$ and $\varphi\left(t_{A}, x, r\right)$ represent the phases of the two images involved in the interferogram generation. As concerns the right hand side of the last identity in eq. (2.1), $\lambda$ is the transmitted signal central wavelength and $d\left(t_{B}, x, r\right)$ and $d\left(t_{A}, x, r\right)$ are the LOS projections of the cumulative deformations at times $t_{B}$ and $t_{A}$, with respect to the instant $t_{0}$ assumed as reference (i.e., $\varphi\left(t_{0}, x, r\right)=0, \forall(x, r)$ ). The second term $\Delta \varphi_{k}^{\text {topo }}(x, r)$ accounts for possible topographic artifacts in the Digital Elevation Model (DEM) we used for removing the topographic phase contribution within the interferogram generation process; the term $\Delta \varphi_{k}{ }^{a t m}$ $\left(t_{B}, t_{B}, x, r\right)$ accomplishes for possible inhomogeneities between the two acquisitions, usually referred to as atmospheric phase artifacts (Goldstein, 1995), and finally the last factor $\Delta n_{k}(x, r)$ accounts for the noise effects.

Equation (2.1) allows us to define a system of $M$ equations in the $N$ unknowns $\varphi\left(t_{i}, x, r\right)$, $\forall i=1, \ldots, N$, whose solution is carried out by applying the Singular Value Decomposition (SVD) method for each coherent pixel, i.e., for each pixel characterized by a small value of the factor $\Delta n_{k}(x, r)$, see eq. (2.1).

In addition we observe that in order to provide an estimate of the LOS deformation signal, an evaluation of the topographic $\left(\Delta \varphi_{k}^{\text {topo }}(x, r)\right)$ and atmospheric $\left(\Delta \varphi_{k}^{a t m}\left(t_{B}, t_{B}, x, r\right)\right)$ phase artifacts is also needed.

In particular, the estimation of the $\Delta \varphi_{k}^{\text {topo }}(x$, $r$ ) factor benefits of the characteristic of this signal component that is correlated with the vector of the spatial baselines (more specifically of the perpendicular baselines component with respect to the radar line of sight) of the interferograms sequence. In particular, the expression of the topographic phase factor in eq. (2.1) is the following:

$$
\Delta \varphi_{k}^{\text {topo }}(x, r) \approx \frac{4 \pi}{\lambda} \frac{B_{\perp k} \Delta z}{r \sin \vartheta}
$$

where in $B_{\perp k}$ represents the perpendicular baseline component relevant to the $k$-th interferogram, $\vartheta$ the SAR sensor look angle and $\Delta z$ the error in the DEM used for the interferogram generation. Accordingly, by substituting eq. (2.2) in eq. (2.1), we may easily obtain as a solution to our system of equations also an estimate of the topographic factor $\Delta_{z}$ shown in eq. (2.2).

As concerns the detection of possible at- 
mospheric artifacts, it is based on the observation that the atmospheric signal phase component is highly correlated in space but poorly in time, see Ferretti et al. (2000). Accordingly, the undesirable atmospheric phase signal is estimated from the time series computed by solving the system of equations based on eq. (2.1), $\forall k \in(1, \ldots, \mathrm{M})$, through the cascade of a lowpass filtering step in the two-dimensional spatial domain followed by a temporal high-pass filtering operation. Following their identification, the atmospheric artifacts are finally removed and the required deformation time series is generated.

As a final remark, we stress that an estimate of the quality retrieval of the detected deformation can be carried out by identifying all the pixels where reliable information has been achieved. For this purpose, we introduce the factor $\gamma$, usually referred to as temporal coherence, that is computed (pixel by pixel) as follows:

$$
\gamma=\frac{\left|\sum_{k=1}^{M} \exp \left[j\left(\delta \phi_{k}^{\text {wrapped }}-\delta \bar{\phi}_{k}\right)\right]\right|}{M} 0 \leq \gamma \leq 1
$$

where $\delta \varphi_{k}^{\text {wrapped }}$ and $\delta \bar{\varphi}_{k}$, represent the $k$-th original wrapped and the «reconstructed» interferogram, respectively, the latter computed from the retrieved results. Note that, for pixels where $\gamma \rightarrow 1$, we expect a nearly perfect retrieval of the original phase. Accordingly we assumed as «coherent pixels» those characterized by a temporal coherence value greater than a selected threshold, for instance $\gamma=0.7$ which is a typical value in DInSAR applications (Lanari et al., 2004a, Borgia et al., 2005).

In summary, through the use of standard multilook DInSAR interferograms the SBAS technique permits us to detect and follow the temporal evolution of surface deformation with high degree of temporal and spatial coverage,

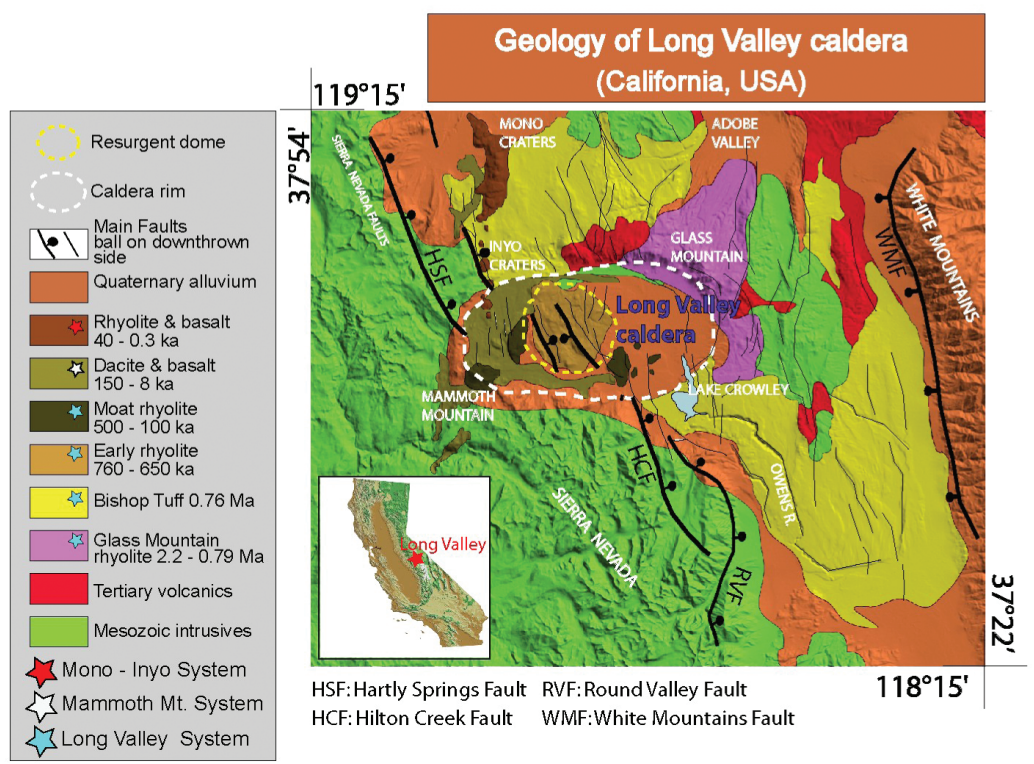

Fig. 1. Simplified geological map of Long Valley caldera superimposed on the shaded relief DEM of the area. Thick lines represent the main regional structures of the Sierra Nevada and White Mountains. Thin lines show the inner structures present in the region (data modified from Bailey, 1989; and Hill and Prejean, 2005). The inset shows the location of the selected test site. 
by using nearly all the available SAR acquisitions and by exploiting SAR data pairs with limited baseline values.

\section{SBAS-DInSAR results}

The following section is dedicated to the investigation of the surface deformation phenomena affecting selected test areas with the SBASDInSAR algorithm. The presented results demonstrate the deformation retrieval capability of the SBAS technique on active volcanic areas, allowing us to detect different deformation patterns and to analyze the temporal evolution of the related displacements.

\subsection{Surface deformation analysis: the Long Valley caldera case study}

\subsubsection{Geological setting}

The Long Valley caldera is an oval depression, east-west oriented, located to northwest of the Owens Valley rift, forming a re-entrance in the Sierra Nevada escarpment (fig. 1). The caldera was formed along a segment of the Sierra Nevada frontal fault where a left-stepping en echelon offset is well developed and the northwest-trending Sierra Nevada front diverges from the more northerly trend of the White Mountains front (Bailey, 1989; Hill and Prejean, 2005).

Volcanism in the Long Valley area (Bailey, 1989, 2004) began about 3.6 Ma B.P. with widespread eruption of trachybasaltic-trachyandesitic lavas (Hill and Prejean, 2005); subsequently, starting from 2.2 Ma B.P., more silicic magma were emitted. The first of these eruptions took place near Glass Mountain on the North-East rim of the actual caldera (fig. 1). At 0.76 Ma B.P., the Bishop Tuff eruption occurred with a catastrophic rupturing of the roof of the magma chamber, resulting in the expulsion of $600 \mathrm{~km}^{3}$ of rhyolite magma. The consequent partial emptying of the chamber caused a collapse of its roof, forming the Long Valley caldera elliptical depression. The resulting ash flow deposits, referred to as Bishop Tuff, cov- ered an area of $1,500 \mathrm{~km}^{2}$ and their distribution is sketched in fig. 1 .

After the caldera collapse, between about 0.7 and 0.6 Ma B.P., a sequence of eruptions took place leading to the formation of the resurgent dome, followed by an interlude of about 100,000 years of volcanic quiescence (Bailey, 1989). Finally, the Long Valley system closed its activity with the emission of the moat rhyolite, between 500 and $100 \mathrm{ka}$ B.P., in a clockwise succession around the resurgent dome, in the north, south-east and west sectors of the moat, respectively (Bailey, 1989; Hill and Prejean, 2005).

Around 150 ka B.P. the activity of Mammoth Mountain system (see fig. 1) located WSW of the caldera started with the emission of dacites and basalts from the intracaldera volcanic vents. The spatial distribution of these vents (strongly aligned along the Sierra frontal trends), combined to the different age of the erupted mafic magmas, suggest that the fissure system propagated northward outside the caldera toward the area of the Mono-Inyo system (Bailey, 1989), a $45 \mathrm{~km}$-north trending volcanic chain, whose most recent eruptive episode occurred between 1325 and 1365 A.D. (Bailey, 1989).

Starting from the end of the 70's and continuing to the present, the Long Valley caldera has experienced seismicity and surface deformation phenomena above the background levels (Langbein et al., 1993, 1995; Battaglia et al., 1999, 2003a,b; Hill et al., 2003; Langbein, 2003; Sorey et al., 2003; Newman et al., 2006). The recent dynamics on the Long Valley caldera has been characterized by a significant unrest period occurred between 1997 and 1998, when an inflation episode, started in mid-1997, exponentially increased during 1997 and was subsequently followed, after mid-1998, by a renewed subsidence phase.

\subsubsection{Results}

In order to investigate the deformation of the Long Valley caldera, we analyzed with the SBAS approach a data set composed by 21 descending orbit SAR images (Track 485, Frame 

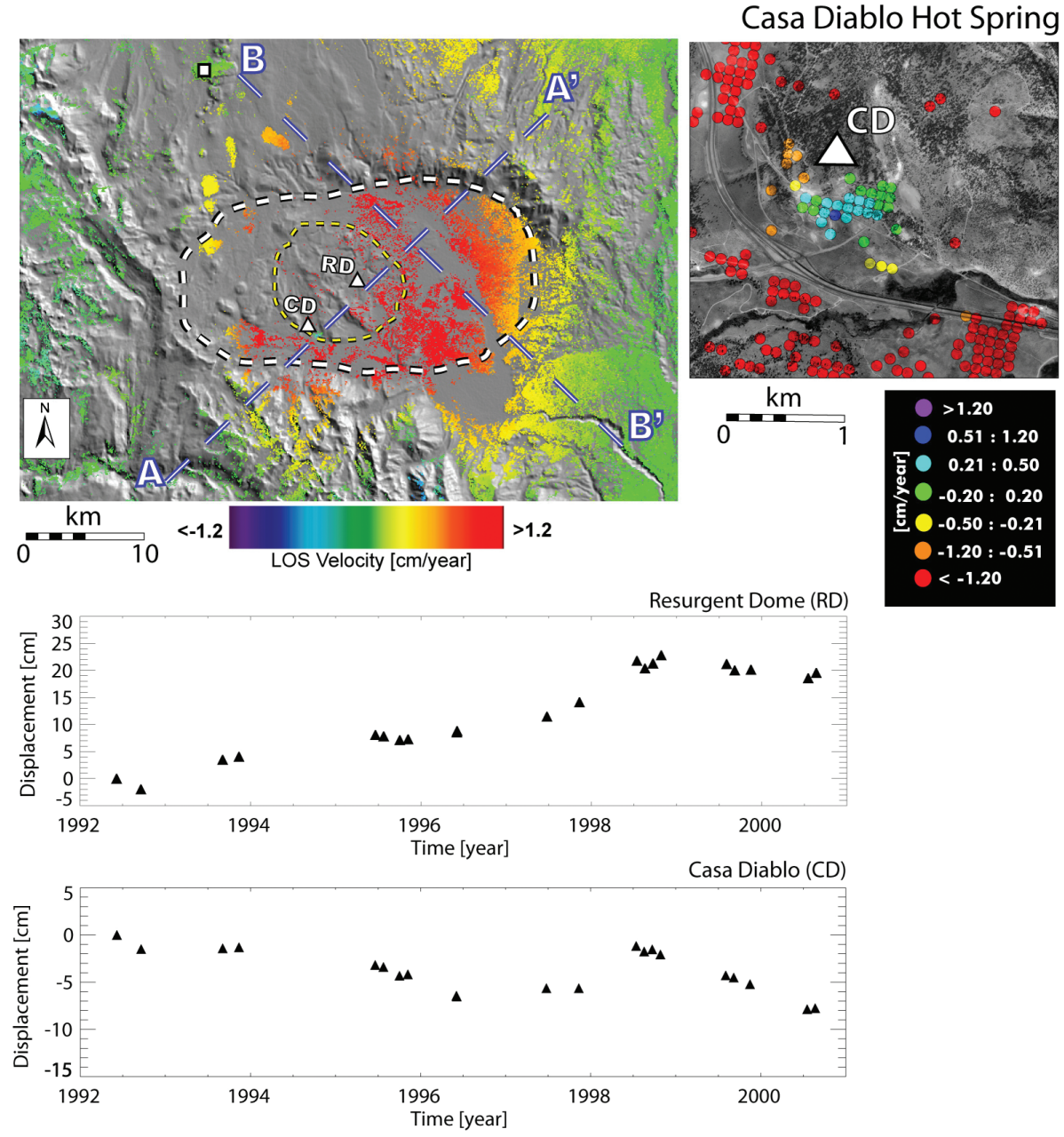

Fig. 2a-d. SBAS-DInSAR results relevant to the Long Valley caldera area. a) Mean LOS deformation velocity map (in color) superimposed on a shaded relief DEM of the area (grey scale). The white triangles (labeled as $\mathrm{RD}$ and $\mathrm{CD}$ ) indicate the two pixels relevant to the plots shown in c-d. The blue dashed lines indicate the two selected cross-sections relevant to the plots shown in the following Figure 3 and labeled as $\mathrm{AA}^{\prime}$ and $\mathrm{BB}^{\prime}$, respectively. The boundaries of the caldera and of the resurgent dome have been identified by the dashed white and yellow lines, respectively. Finally, the white square identifies the reference SAR pixel. b) Zoomed view of the Casa Diablo Hot Spring: the DInSAR mean deformation velocity map, superimposed on an orthophoto of the zone, is shown highlighting the location of the pixel labeled as CD. c) DInSAR LOS deformation time series for the pixels marked by the white triangle labeled in (a) as RD. d) DInSAR LOS deformation time series for the pixels marked by the white triangle labeled in (a) as $\mathrm{CD}$.

2845), acquired by the ERS- $1 / 2$ sensors spanning the time interval from June 1992 to $\mathrm{Au}$ gust 2000. The interferogram generation was carried out by exploiting a Shuttle Radar
Topography Mission (SRTM) DEM (Rosen et al., 2001) of the study area and precise orbital information. Moreover, a complex multilook operation with 4 range looks and 20 azimuth 
looks was performed, resulting in a pixel size of approximately $100 \mathrm{~m} \times 100 \mathrm{~m}$. Overall, we generated 44 interferograms characterized by a maximum perpendicular baseline value of about $350 \mathrm{~m}$ and a temporal separation less than 4 years. Note that the investigated SAR data set includes the same ERS tracks considered in the study presented by Tizzani et al. (2007) but now the processed area is limited to the Long Valley caldera, only.

As a first result of the SBAS-DInSAR analysis, we present in fig. 2a the geocoded DInSAR mean deformation velocity map, computed in a set of coherent pixels only, and superimposed on a $50 \mathrm{~km} \mathrm{x} 40 \mathrm{~km}$ shaded relief DEM of the area. We stress that this kind of representation is particularly effective and provides immediate information on the observed deformation. Indeed, an uplift phenomenon (revealed by a sensor to target range decrease) affecting a large area is clearly visible within the Long Valley caldera and the Inyo chain located close to the north-west edge of the caldera (fig. 2a). We observe that the maximum value of the mean deformation uplift velocity within this area is about $3 \mathrm{~cm} /$ year in correspondence to the pixel located in the resurgent dome zone identified by the white triangle labeled as RD in fig. 2 a.

In addition to this main phenomenon, a more careful analysis, carried out on the data presented in fig. 2a, reveals a further, more localized deformation pattern. In particular, we identified a rather localized subsidence phenomenon (revealed by a corresponding sensor to target range increase) inside the caldera which affects the Casa Diablo geothermal zone, as shown in the zoomed view of fig. $2 b$; in this case we measured a maximum deformation velocity value of about $0.5 \mathrm{~cm} /$ year in correspondence to the pixel identified by the white triangle labeled as CD in fig. 2a.

We further remark that the SBAS technique allows us to retrieve, for each coherent pixel, not only the mean deformation velocity signal (shown in figs. 2a-b) but also the corresponding
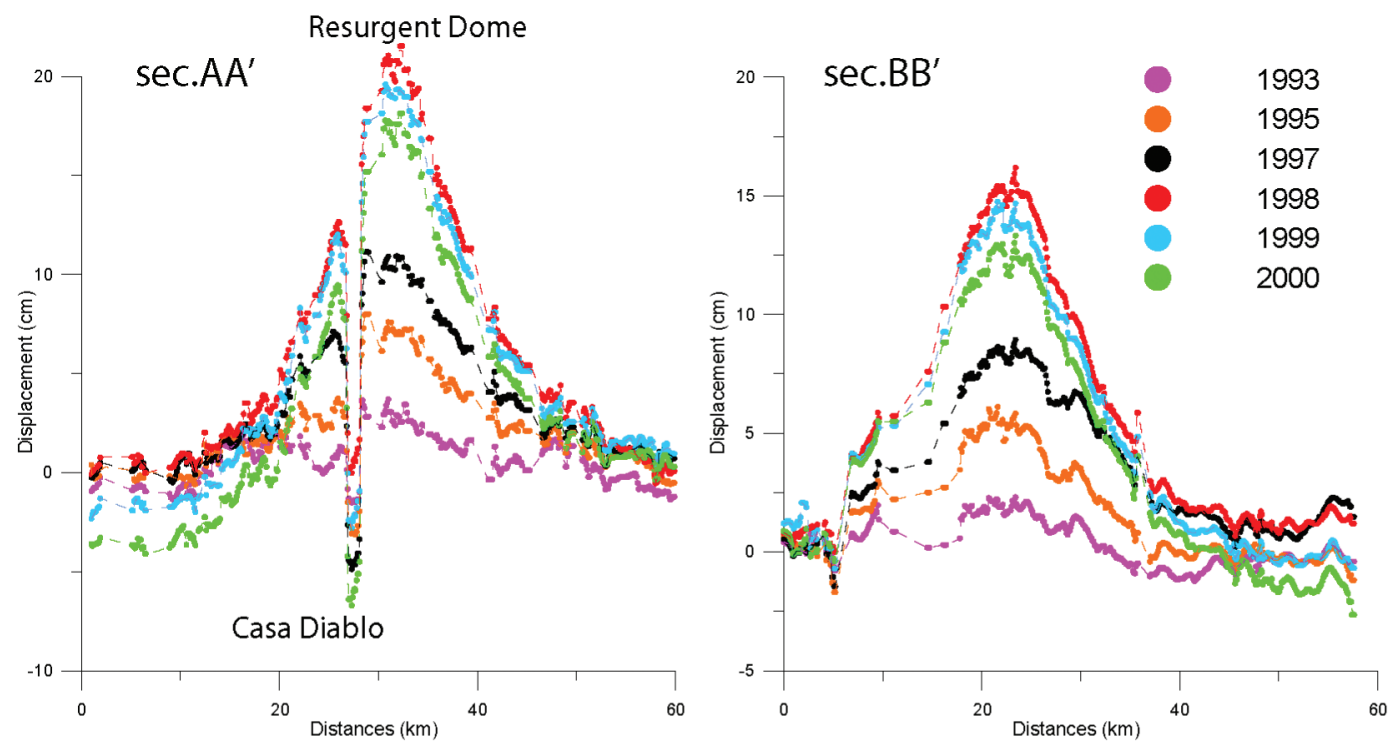

Fig. 3a,b. Plots of the detected LOS displacements measured in the first SAR acquisition for each observation year $(1993,1995,1997,1998,1999,2000)$, and evaluated with respect to June 1992, for the two cross-sections labeled in Figure 2a as AA' (a) and BB' (b), respectively. Note also that in (a) the Resurgent Dome and the Casa Diablo Hot Spring locations have been highlighted. 
displacement time series. This is a crucial information for the analysis of dynamic deformation phenomena such as those affecting volcanic areas, characterized by succession of background deformation and unrest crises. To give an idea of the deformation time series achievable with the application of the SBAS algorithm in such areas, we present in figs. 2c-d two examples relevant to the investigated zone. The first shows the temporal evolution of the displacement (see fig. 2c) relevant to the pixel marked as RD in Fig. 2a; note that the 1997-1998 unrest phenomenon is evident in the plotted time series, leading to a LOS maximum displacement exceeding $20 \mathrm{~cm}$. The second is relevant to the pixel labeled as CD in figs. $2 a-b$; in this case, it clearly appears that the general subsidence trend due to the geothermal station activity, is interrupted by the caldera uplift during the unrest episode (fig. $2 \mathrm{~d}$ ).

In addition, a joint exploitation of the spatial and temporal deformation signals can also be made. To achieve this task, we selected two different sections in the study area, labeled as $\mathrm{AA}^{\prime}$ and $\mathrm{BB}^{\prime}$ and identified by the dashed blue lines in fig. 2a. For each of these, we plotted (fig. 3) the detected LOS deformation corresponding to the first date of each year of the investigated SAR image sequence and evaluated with respect to June 1992, which is assumed as time reference. Note that we did not consider in our cross-sections the data relevant to 1996 because only two acquisitions were available to us with a very short temporal separation (1 day), thus not guaranteeing an effective filtering of the atmospheric phase artifacts (Casu et al., 2006).

From the analysis of these plots a sequence of three different deformation patterns clearly appears: a 1992-1997 uplift background, a 1997-1998 unrest phenomenon and a 19982000 subsidence phase. Moreover, the detected maximum displacement area, located in the resurgent dome, does not significantly change its location throughout the observation period and, in particular, passing from the background to the unrest and, finally, to the subsidence phase, as reported by Battaglia et al. (2003a) and Langbein (2003).

In addition, in section $\mathrm{AA}^{\prime}$ (fig. 3a), it is clearly visible the local subsidence trend, due to the geothermal station activity of Casa Diablo which is interrupted by the caldera during the unrest episode. This already known effect (Howle et al., 2003) enforces the retrieval capability of the SBAS algorithm to detect and follow such localized effects even if they occur in areas with a significantly different deformation behavior.

\subsection{Surface deformation analysis: the Mt. Etna volcano case study}

\subsubsection{Geological setting}

Mt. Etna is one of the largest and most active continental volcanoes on Earth. Since its first activity $500 \mathrm{ka}$ B.P., the volcano has grown to cover more than $1250 \mathrm{~km}^{2}$ and, rising to 3350 $\mathrm{m}$ a.s.l., today dominates the eastern coastline of the Sicily region (Italy). It lies on the intersection of three main seismically active system faults NNE-SSW, ENE-WSW and NNW-SSE oriented and is located between two geodynamical systems: the Apennine-Maghrebian chain to the north and the Hyblean-Maltes foreland to the south (Continisio et al., 1997; Monaco et al., 1997).

Four different phases of the ancient volcanic activity in the Etnean area can be identified (Tanguy et al., 1997; Behncke, 2001). The early one (500-200 ka B.P.), known as «Pre-Etnean», mainly consisted of tholeiitic pillow lavas and hyaloclastites, outcropping at Acicastello, $10 \mathrm{~km}$ north of Catania, and nearby locations (fig. 4). About 300 ka B.P., several eruptions mainly occurred in the Mt. Etna south-western sector, producing transitional tholeiitic and alkalic basalts. The second phase (170-100 ka B.P.), referred to as «Trifoglietto I», began with more localized eruptions. It is assumed that a first large stratovolcano formed in the 130-100 ka B.P. period, erupting alkalic basalts and hawaiites magmas (Romano, 1982). The third phase (about 100-60 ka B.P.), named «Trifoglietto II», was characterized by the building of several overlapping stratovolcanoes, while during the last phase (35-15 ka B.P.), the growth of the Mongibello stratovolcano occurred.

The construction of the edifice was often in- 
terrupted by periods of collapses within and around the summit area. The most recent one (after 15 ka B.P.) formed the "Valle del Bove» (fig. 4), a keyhole-shaped depression $1 \mathrm{~km}$ deep, $5 \mathrm{~km}$ wide and $7 \mathrm{~km}$ long, located on the eastern flank of the volcano. This sector collapse produced a debris avalanche, whose deposits underlie a thick succession of fluvial sediments, known as «Chiancone», outcropping on the lower eastern flank of Mt. Etna (Calvari et al., 1998), see fig. 4.

During historical times, the Mt. Etna activity has been essentially effusive and most lavas have erupted from vents outside the summit cone, aligned along three main structural trends NNW-SSE, N-S and NE-SW oriented (fig. 4). Before the 17th century, the volcanic activity is poorly documented, but probably was dominated by flank eruptions (Behncke, 2001). The 17 th century was characterized by several eruptions; some of these were unusually character- ized by long duration (1614-1624, 1634-1638, 1651-1653) and very voluminous lava flows (1669, with about $1 \mathrm{~km}^{3}$ of magma erupted). During the 18th and 19th centuries there were many flank eruptions; the most remarkable ones occurred in 1755 and 1865, respectively. The former took place on the eastern flank of the volcano and caused a lahar that, rushing down through the Valle del Bove, reached the sea. The latter involved the north-eastern flank and represents the largest eruption to have occurred after the 1669 one (Romano and Sturiale, 1982). Since 1865, flank eruptions have been occurred in clusters separated by about 20 years of quiescence: 1874-1892, 1908-1928, 1942-1951, 1971-1993.

The recent volcanic activity was located at the summit craters and expressed by the JulyAugust 2001 (fig. 4), October 2002-January 2003 (Neri et al., 2005) and September 2004March 2005 (Bonaccorso et al., 2006) eruptions.
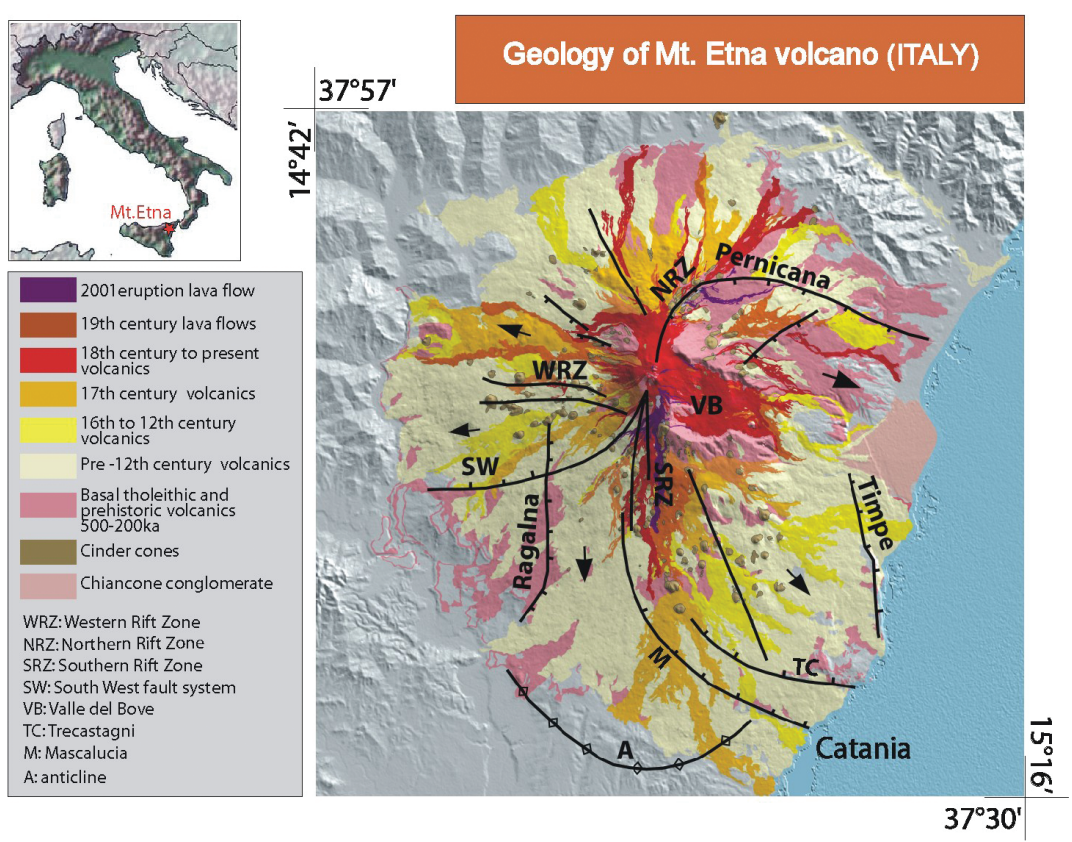

Fig. 4. Simplified geological map of Mt. Etna volcano superimposed on the shaded relief DEM of the area. The thick lines represent the main regional structures present in the area. The arrows indicate the general sense of flank motion. The inset in the upper left corner shows the location of the study area. 


\subsubsection{Results}

At variance with the Long Valley caldera case study, in this case we address the capability of the SBAS algorithm to operate in a multiple-orbit context thus considering, for this purpose, 58 ascending (Track 129, Frame 747) and 55 descending (Track 222, Frame 2853) ERS$1 / 2$ SAR images spanning the 1992-2001 time interval. By exploiting these data sets and imposing that the perpendicular and temporal baseline values were smaller than $160 \mathrm{~m}$ and 4 years, respectively, 84 interferograms for the ascending orbits and 125 for the descending ones, were computed.

The availability of both ascending and descending SAR data set allowed us not only to detect the ground deformation in the corresponding radar line of sight, as shown in section 3.1.2, but also to discriminate the vertical and east-west components of the displacement. To achieve this task, we exploited the sum and the difference of the mean surface velocity maps computed from the ascending and descending orbits, respectively, on pixels common to both maps.

More specifically, the sum is essentially related to the vertical component of the ground deformation, while the difference accounts for the east-west displacement component, only. Note that, because of the polar direction of the sensor orbits, the north-south deformation component cannot be detected: a more detailed discussion on this topic can be found in Manzo et al. (2006).

Following the previous discussion, we present in figs. 5a,b the achieved vertical and eastwest velocity maps, evaluated with respect to a pixel located in Catania (identified with a white square in fig. 5a) and superimposed on a shad-

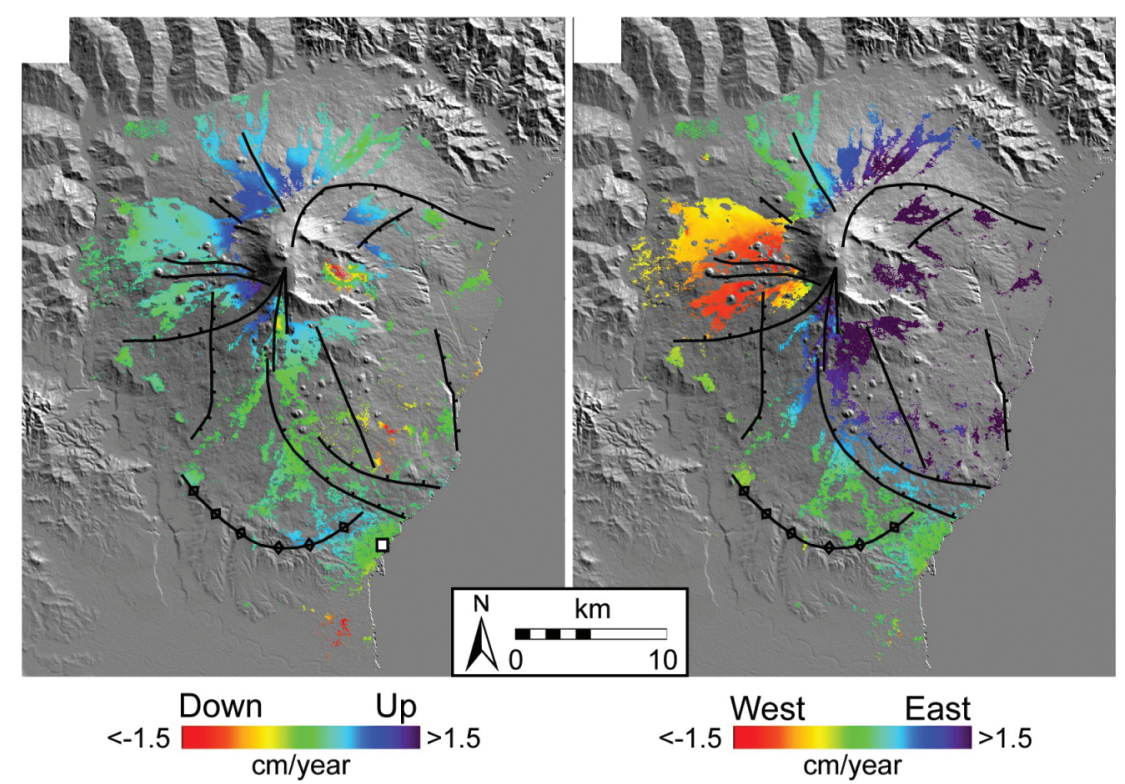

Fig. 5a,b. SBAS-DInSAR results relevant to Mt. Etna volcano. a) Mean vertical deformation velocity map (in color) superimposed on a shaded relief DEM of the area (grey scale) obtained by exploiting the sum of the mean deformation velocity maps computed from the ascending and descending orbits, in the common coherent pixels. The white square identifies the reference SAR pixel. b) Mean east-west deformation velocity map (in color) superimposed on a shaded relief DEM of the area (grey scale) obtained by exploiting the difference of the ascending and descending mean velocity maps. The main regional structures present in the area have been also highlighted (see fig. 4). 
ed relief DEM of the study area. The vertical velocity map (fig. 5a) clearly shows a pronounced bulge along the basal anticline (labeled as A in fig. 4) and a significant uplift of the summit region, northern and north-eastern sectors of the volcano. Moreover, in the Valle del Bove area a subsidence pattern also appears, reaching a maximum velocity value of about $2.4 \mathrm{~cm} /$ year. As concerns the east-west velocity map, shown in fig. 5b, we can observe two main deformation phenomena. The first is relevant to the motion of the western flank toward west and of the eastern flank toward east (with velocity values greater than $1.5 \mathrm{~cm} /$ year); the second accounts for the deformation across the southern and eastern sectors, partitioned between the Trecastagni-Mascalucia and the Ragalna transtensional faults (see figs. 4 and $5 b$ ) as also recently shown by Neri et al. (2007).

The observed deformation pattern is not limited to its eastern and southern flanks but also involves the western sector (Lundgren et al., 2004) and is in agreement with the symmetric spreading model proposed by Merle and Borgia (1996).

\subsection{Surface deformation analysis: the Campi Flegrei caldera case study}

\subsubsection{Geological setting}

Campi Flegrei is a quaternary nested caldera located to the west of the city of Napoli (Italy), in the north-eastern sector of the Phlegrean volcanic district, and resulted from two major collapse events related to the Campanian Ignimbrite (37 ka B.P.) (Barberi et al., 1978) and the Neapolitan Yellow Tuff (12 ka B. P.) (Lirer et al., 1987; Scandone et al., 1991; Orsi et al., 1992, 1999) eruptions, respectively. Overall, the morphology of the area can be regarded as the result of deformation episodes related both to regional tectonics, which generated NW-SE and NE-SW oriented fault systems, and volcanic processes. The latter produced inside the caldera a significant deviation of the structural regional trends (fig. 6), due to the interaction between the local vertical maximum stress (associated with the dynamics of the magmatic system), and the horizontal intermediate stress which is related to the regional structures (Johnson, 1970).

Historically, the Campanian Ignimbrite (CI) event represents the highest magnitude explosive eruption to have occurred in the Mediterranean area in the last $200 \mathrm{ka}$. It led to the formation of a caldera and caused the subsidence of the whole Phlegrean area, covering an area of about 7000 $\mathrm{km}^{2}$ with approximately $80 \mathrm{~km}^{3}$ of pyroclastic flows and fall deposits, not outcropping today in the analyzed area because of erosion phenomena, alluvium processes and emplacements of volcanic deposits related to successive eruptions (Lirer et al., 1987; Scandone et al., 1991; Rosi et al., 1996). Between 37 and $12 \mathrm{ka} \mathrm{B.P.} \mathrm{volcanism}$ produced deposits whose residues are still visible today at the Campanian Ignimbrite caldera periphery, see fig. 6 .

The subsequent eruption of the Neapolitan Yellow Tuff (NYT) formed a less extended caldera inside the Campanian Ignimbrite one, producing about $10-20 \mathrm{~km}^{3}$ of magmas, whose outcrops are distributed on a large area outside the NYT caldera rim (Lirer et al., 1987; Scandone et al., 1991), see fig. 6.

The 11-9 ka B.P. period was characterized by a sequence of eruptions that generated a series of monogenic edifices (Lirer et al., 1987; Scandone et al., 1991). Moreover, in the 10-5 ka B.P. time interval, the bottom of the NYT caldera experienced an uplift phenomenon, whose effect is still visible along the coast-line to the north of the gulf of Pozzuoli. This uplift phase was accompanied and followed by a renewed volcanic activity with the AgnanoMonte Spina (4 ka B.P.), Astroni (3.7 ka B.P.) and Averno (3.7 ka B.P.) eruptions (Lirer et al., 1987; Scandone et al., 1991). This period was followed by a long quiescence phase, lasting about 3000 years (Rosi and Sbrana, 1987) and interrupted by the Monte Nuovo eruption (1538 A.D.), which represents the most recent eruptive event to have occurred at Campi Flegrei (Di Vito et al., 1987).

Starting from the end of the 1960's the caldera has experienced rapid, large amplitude uplift episodes followed by longer term subsidence (Dvorak and Gasparini, 1991; Lundgren et al., 2001). In particular, during the 1969- 


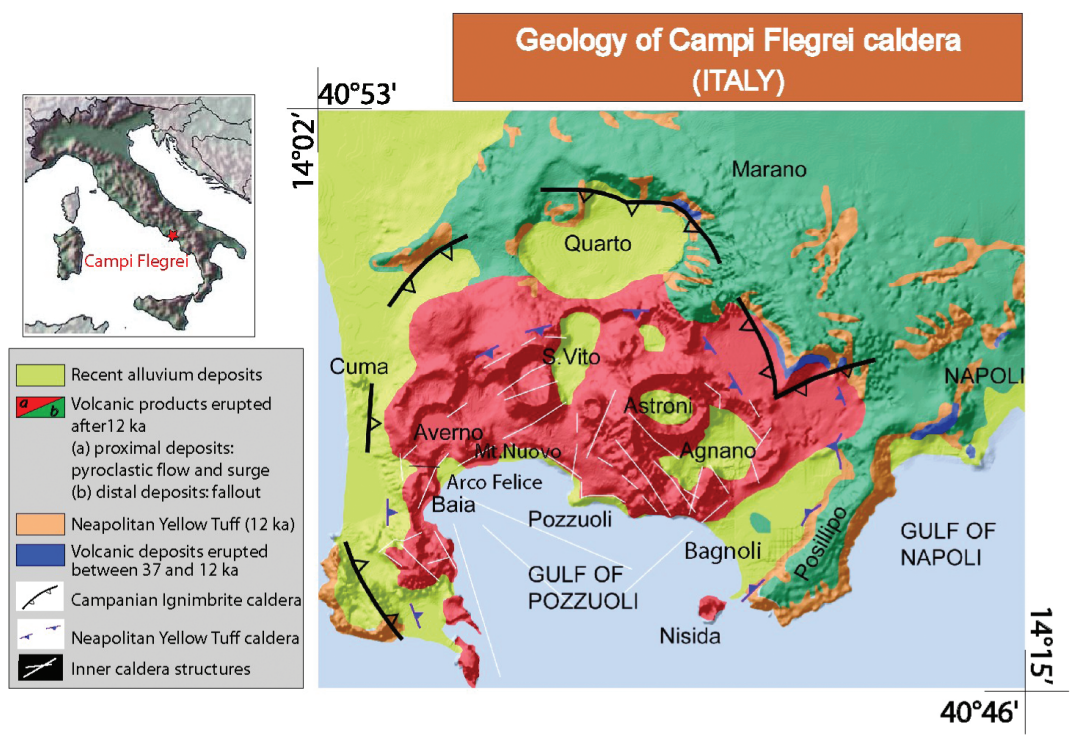

Fig. 6. Simplified geological map of Campi Flegrei caldera superimposed on the shaded relief DEM of the area. The inset in the upper left corner shows the location of the study area.

1984 period the caldera deformation process produced a cumulative uplift phenomenon of more than $3.5 \mathrm{~m}$ with a maximum rate value of about $1 \mathrm{~m} /$ year in the 1982-1984 time interval (Orsi et al., 1999; De Natale et al., 2006) and, more recently, from March to August 2000, when a deformation of about $5 \mathrm{~cm}$ was measured (Osservatorio Vesuviano, 2000; Lanari et al., 2004b).

\subsubsection{Results}

In this section, in order to investigate the deformation field in the Campi Flegrei caldera, we take advantage of the SBAS-DInSAR algorithm capability to generate time series and mean deformation velocity maps by jointly exploiting SAR data acquired by different satellites. In this context, we refer to the extended SBAS approach proposed by Pepe et al. (2005) which can be applied to combine interferometric SAR data produced by different (but with the same illumination geometry) radar sensors, thus extending the temporal analysis of the de- tected deformation: this is, in particular, the case of the ERS and ENVISAT-IS2 data integration. It must also be observed that, because the ERS-1/2 satellites are twin sensors, the corresponding interferometric products can be here regarded as achieved by a unique sensor. In our experiment, we considered a set of 64 ERS1/2 SAR data, spanning the 1992-2005 time interval, and 14 ENVISAT-IS2 SAR data collected since 2002, both acquired along the descending orbits (Track 36, Frame 2781). Overall, we generated 222 interferograms characterized by a perpendicular baseline value smaller than 400 $\mathrm{m}$ and a maximum temporal separation of about 4 years.

First we present in fig. 7 the cumulative LOS deformation maps computed with respect to the first available SAR image (June 8, 1992) shown in fig. 7a in five properly selected SAR temporal acquisitions (fig. 7b-f). Note that the map in fig. 7a contains only null deformation values, since it represents the temporal reference for the SBAS-DInSAR algorithm (see section 2 for more details). Moreover, Figs. 7b-c represent the cumulative deformation measured 
on January 1996 and January 2000, respectively. It is evident that throught the whole 19922000 period a subsidence phenomenon affected a larger and larger area within the Campi Flegrei caldera (centered in the Pozzuoli area, fig. $7 b-c)$ reaching a maximum deformation value of about $25 \mathrm{~cm}$. The effect of the subsequent uplift event that occurred during 2000 is highlighted in fig. $7 \mathrm{~d}$ where the cumulative deformation measured in the SAR acquisition relevant to the maximum uplift (July 2000) is pre- sented. A renewed subsidence phase mostly compensated this surface inflation, as confirmed by the comparison between the maps computed on January 2000 and January 2002, see fig. 7c and fig. 7e, respectively. Finally, the map evaluated in October 2004 (fig. 7f) shows the persistence of the renewed subsidence trend, even if with a lower deformation rate with respect to the 1992-2000 time period.

The presented maps shown in fig. 7a-f give us both spatial and temporal information on the
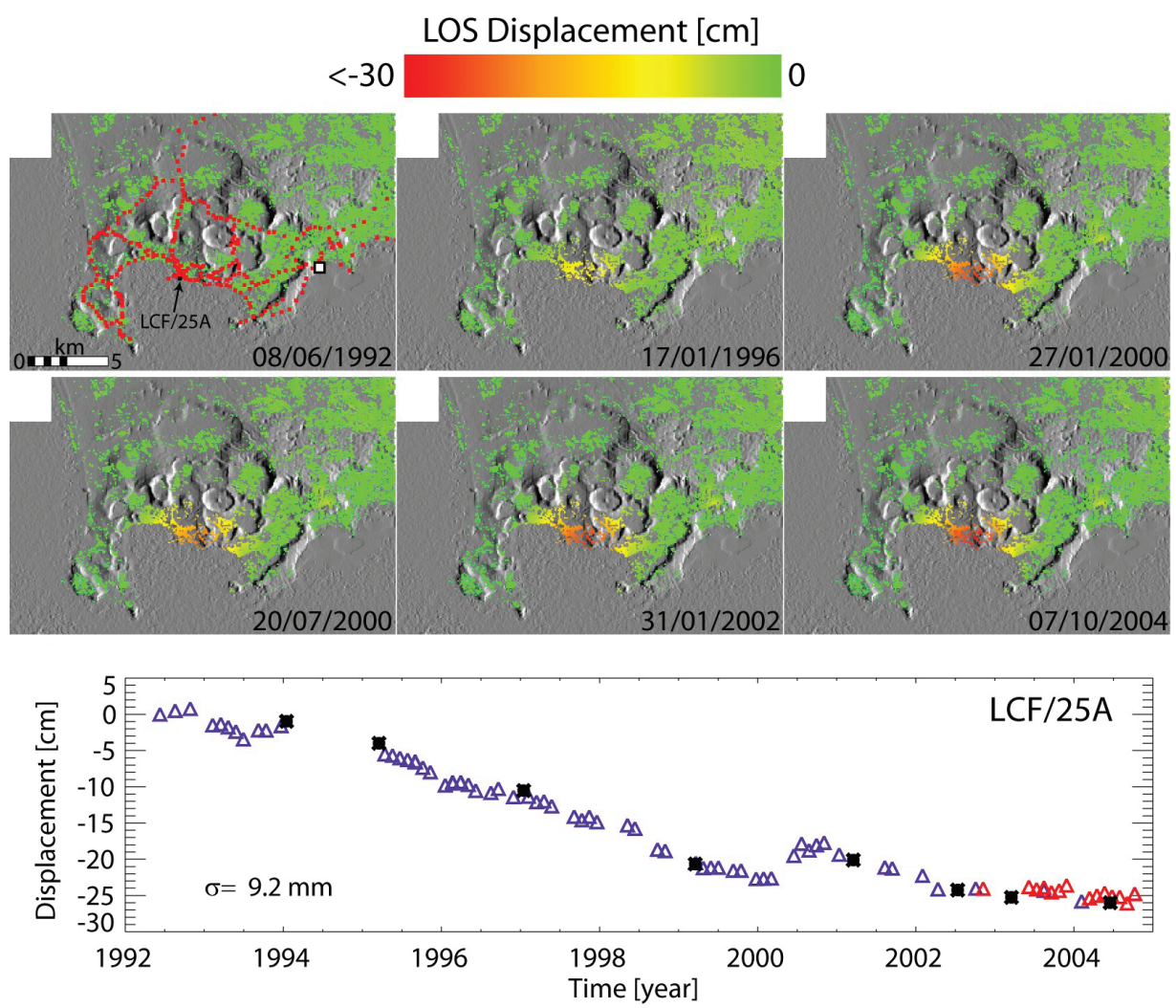

Fig. 7a-g. SBAS-DInSAR results relevant to the Campi Flegrei caldera. a) Leveling network layout (red squares) superimposed on the displacement map (green color) relevant to the first temporal acquisition (June 8, 1992) of the SAR data set. The location of the LCF/25A leveling benchmark has been highlighted. The white square identifies the reference SAR pixel. b-f) Displacement maps relevant to the January 17, 1996, January 27, 2000, July 20, 2000, January 31, 2002, October 10, 2004 acquisitions, respectively. g) Comparison between the DInSAR LOS deformation time series (ERS data: blue triangles, ENVISAT data: red triangles) and the corresponding leveling measurements, projected on the radar LOS (black stars), for the pixel labeled in (a) as $\mathrm{LCF} / 25 \mathrm{~A}$. The standard deviation value of the differences between the DInSAR and the LOS-projected leveling measurements has been also reported. 
retrieved surface deformation field, representing the cumulative displacement in selected time intervals. To better appreciate the dynamics of the detected deformation throughout the observation period, we present in fig. $7 \mathrm{~g}$ the DInSAR time series relevant to a pixel located in the maximum displacement area. The previous mentioned phases of the deformation process are easily identified: the 1992-2000 subsidence, the 2000-2001 uplift, the 20022004 renewed deflation. Moreover, it is worthy to note how the ENVISAT data (red triangles in fig. $7 \mathrm{~g}$ ) significantly extend the ERS (blue triangles in fig. $7 \mathrm{~g}$ ) time series, permitting us to better understand the displacement phenomenon.

Since a large spirit leveling network, periodically surveyed by the INGV-Osservatorio Vesuviano and composed by 322 benchmarks on about 120 linear $\mathrm{km}$, is deployed in the Campi Flegrei area (fig. 7a), we were able to perform a sample comparison between DInSAR and leveling data, thus better clarifying the different characteristics of the two measurement systems.

Apart from the generally good agreement between the two methodologies employed, it is evident from the observation of fig. $7 \mathrm{~g}$ that the higher number of SAR acquisitions (blue and red triangles) with respect to the leveling data (black asterisks) represents crucial information to be taken into account to better comprehend the deformation dynamics. In order to provide quantitative information as well, we computed the standard deviation $(\sigma)$ of the difference between the DInSAR and the LOS-projected leveling time series, the latter interpolated via a linear regression within the interval common to the SAR data. The measured standard deviation value (about $9 \mathrm{~mm}$ ) is smaller than the corresponding one $(10.9 \mathrm{~mm})$ reported in Casu et al. (2006) but we interpreted this difference as due to the use in the present work of a more statistically significant SAR data set, composed of a wider number of acquisitions in time.

\section{Discussions and conclusions}

In this work we exploited the capability of the SBAS-DInSAR algorithm to retrieve the surface deformation relevant to geological and geophysical phenomena affecting active volcanic areas. More specifically, we concentrated on the SBAS algorithm features to provide accurate spatial and temporal information on the analyzed displacement, via the generation of deformation time series, thus permitting us to detect and investigate geological phenomena at both large and local scale. In particular, we focused on three selected case study areas: the Long Valley caldera (eastern California), Mt. Etna volcano (Italy) and the Campi Flegrei caldera (Italy).

First, we presented the SBAS-DInSAR standard results, consisting in both the mean deformation velocity maps and the corresponding deformation time series in the radar LOS direction, obtained by investigating the Long Valley caldera area. In addition, by exploiting these data, we also considered two properly selected cross sections across the caldera area and performed a joint space-time analysis on the detected LOS deformation.

Subsequently, we exploited the multi-orbit SBAS algorithm capability to discriminate the east-west and the vertical components of the detected displacements at Mt. Etna volcano area: this task was easily accomplished by combining the information achievable from multiple radar LOS observations. The detected deformation patterns exhibited a good fit with respect to the main geological structures of the zone and are in agreement with a symmetrical spreading model of the volcano edifice.

Finally, we addressed the multi-sensor capability of the SBAS algorithm to generate time series and mean deformation velocity maps starting from a set of SAR data acquired by different satellites. In particular, we referred to the Campi Flegrei caldera test site and processed the relevant SAR data set composed of both the ERS and the ENVISAT acquisitions. The application of the extended SBAS-DInSAR approach permitted us to significantly extend the temporal analysis and to better understand the displacement phenomenon.

The presented results show the effectiveness and the capability of the SBAS technique to investigate the deformation field in active vol- 
canic areas and the potential of the DInSAR methodologies within routine surveillance scenario. Moreover, the possibility to invert the DInSAR data, in order to model both deep geological structures and magmatic sources, represents one of the main developments in the framework of source modeling applied to active volcanic regions.

\section{Acknowledgements}

This work has been partially sponsored by the European Community on Provision 3.16, under the project of the Regional Center of Competence «Analysis and Monitoring of the Environmental Risk» (CRdC-AMRA), by the Italian Space Agency and the (Italian) National Group for Volcanology (GNV). We thank the European Space Agency, which provided the ERS SAR data relevant to the Long Valley caldera through the WInSAR data archive in collaboration with Paul Lundgren (JPL, Caltech) and Andrew Hooper (Stanford University); the ERS data relevant to Mt. Etna volcano are within the Cat-1 1127 while the ERS/ENVISAT-IS2 SAR data relevant to the Naples bay area within the Cat-1 1065 and 1318. Moreover, the DEMs of the investigated zones have been achieved through the SRTM archive while precise ERS-1/2 satellite orbit state vectors have been made available by the Technical University of Delft, The Netherlands; orthophotos of Long Valley are courtesy of USGS. Finally, the authors also want to thank the Osservatorio Vesuviano which provided the leveling measurements of the Naples bay site and, in particular, G. P. Ricciardi. Moreover, special thanks go to Riccardo Lanari for his continuous help and support.

\section{REFERENCES}

BAILEY, R.A. (1989): Geologic Map of Long Valley Caldera, Mono-Inyo craters volcanic chain, and vicinity, Eastern California, to accompany map I-1993, Department of Interior USGS.

BAILEY, R.A. (2004): Eruptive history and chemical evolution of the precaldera and postcaldera basalt-dacite sequences, Long Valley, California: implications for magma sources, current magmatic unrest, and future volcanism, U.S. Geol. Surv. Prof. Pap. 1692.

Barberi, F., F. Innocenti, L. Lirer, R. Munno, T. PescaTORE and R. SANTACROCE (1978): The Campanian Ignimbrite: a major prehistoric eruption in the Neapolitan area (Italy), Bull. Volcanol., 41 (1), 1-22.

Battaglia, M., C. Roberts and P. Segall (1999): Magma intrusion beneath Long Valley caldera confirmed by temporal changes in gravity, Science, 285.

Battaglia, M., P. Segall, J. Murray, P. Cervelli and J. LANGBein (2003a): The mechanics of unrest at Long Valley caldera, California: 1. Modeling the geometry of the source using GPS, leveling and two-color EDM data, J. Volcanol. Geotherm. Res., 127 (3-4), 195-217.

Battaglia, M., P. Segall and C. Roberts (2003b): The mechanics of unrest at Long Valley caldera, California. 2. Constraining the nature of the source using geodetic and micro-gravity data, J. Volcanol. Geotherm. Res., 127 (3-4), 219-245.

BeHNCKE, B. (2001): Volcanism in the Southern Apennines and Sicily, in Anatomy of an Orogen: the Apennines and Adjacent Mediterranean Basins, edited by G.B. VAI and I.P. MARTINI (Kluwer Academic Publishers, Dordrecht-Boston-London), 105-120.

Berardino, P., G. Fornaro, R. Lanari and E. Sansosti (2002): A new Algorithm for Surface Deformation Monitoring based on Small Baseline Differential SAR Interferograms, IEEE Trans. Geosci. Remote Sensing, 40 (11), 2375-2383.

Bonaccorso, A., A. Bonforte, F. Guglielmino, M. PALANO and G. Pugliesi (2006): Composite ground deformation pattern forerunning the 2004-2005 Mt. Etna eruption, J. Geophys. Res., 111, B12207, doi: 10.1029/2005JB004206.

Borgia, A., P. Tizzani, G. Solaro, M. Manzo, F. Casu, G. Luongo, A. Pepe, P. Berardino, G. Fornaro, E. Sansosti, G. P. Ricciardi, N. Fusi, G. Di Donna and R. LANARI (2005): Volcanic spreading of Vesuvius, a new paradigm for interpreting its volcanic activity, Geophys. Res. Lett., 32, L03303, doi: 10.1029/ 2004 GL022155.

Calvari, S., L. Tanner and G. Groppelli (1998): Debrisavalanche deposits of the Milo Lahar sequence and the opening of the Valle del Bove on Etna volcano Italy, $J$. Volcanol. Geotherm. Res., 87, 193-209.

Casu, F., M. Manzo and R. LANARI (2006): A Quantitative Assessment of the SBAS Algorithm Performance for Surface Deformation Retrieval from DInSAR Data, Remote Sensing Environ., 102, 195-210, 10.1016/ j.rse.2006.01.023.

Continisio, R., F. Ferrucci, G. Gaudiosi, D. Lo Bascio and G. Ventura (1997): Malta escarpment and Mt. Etna: early stages of an asymmetric rifting process? Evidences from geophysical and geological data, Acta Volcanol., 9, 45-53.

Costantini, M. and P.A. Rosen (1999): A generalized phase unwrapping approach for sparse data, in IGARSS'99 Proceedings, June 1999, Hamburg, Germany, 267-269.

Crosetto, M., B. CRipPa and E. Biescas (2005): Early detection and in-depth analysis of deformation phenomena by radar interferometry, Engin. Geol., 79 (1-2), 8191.

De Natale, G., C. Troise and C.R.J. Kilburn (2006): 
Mechanism of activity and unrest at large calderas, $\mathrm{Ge}$ ol. Soc. London, Spec. Vol., London.

Di Vito, M.A., L. Lirer, G. Mastrolorenzo and G. Rolandi (1987):The Monte Nuovo eruption Campi Flegrei, Italy, Bull. Volcanol., 49, 608-615.

DVORAK, J.J. and P. GASPARINI (1991): History of earthquakes and vertical ground movement in Campi Flegrei caldera, Southern Italy; comparison of precursory events to the A.D. 1538 eruption of Monte Nuovo and of activity since 1968, J. Volcanol. Geotherm. Res., 48, 77-92.

Ferretti, A., C. Prati and F. Rocca (2000): Non-linear Subsidence Rate Estimation Using Permanent Scatterers in Differential SAR Interferometry, IEEE Trans. Geosci. Remote Sensing, 38 (5), 2202-2212.

GABriel, A.K., R.M. GoldsteIN and H.A. ZEBKER (1989): Mapping small elevation changes over large areas: differential interferometry, J. Geophys. Res., 94, 9183-9191.

Goldstein, R.M. (1995): Atmospheric limitations to repeat-track radar interferometry, Geophys. Res. Lett., 22, 2517-2520.

HiLl, D.P. and S. PrejeAn (2005): Magmatic unrest beneath Mammoth Mountain, California, J. Volcanol. Geotherm. Res, 146 (4), 257-283.

Hill, D.P., J.O. LANGBEIn and S. PreJeAn (2003): Relations between seismicity and deformation during unrest in Long Valley Caldera, California, from 1995 through 1999, J. Volcanol. Geotherm. Res., 127 (3-4), 175-193.

Hooper, A., H. ZebKer, P. Segall and B. Kampes (2004): A new method for measuring deformation on volcanoes and other natural terrains using InSAR persistent scatterers, Geophys. Res. Lett., 31, L23611, doi: 10.1029/2004GL021737.

Howle, J.F., J.O. LANGBein, C.D. FARrar and S.K. WiLKINSON (2003): Deformation near the Casa Diablo geothermal well field and related processes Long Valley caldera, Eastern California, 1993-2000, J. Volcanol. Geotherm. Res, 127 (3-4), 365-390.

Johnson, A.M. (1970): Physical Processes in Geology (San Francisco, Freeman, Cooper \& Co.), pp. 577.

LANARI, R., P. Lundgren, M. MANZO and F. CASU (2004a): Satellite radar interferometry time series analysis of surface deformation for Los Angeles, California, Geophys. Res. Lett., 31, L23613, doi: 10.1029/ 2004GL021294.

lanari, R., P. Berardino, S. Borgström, C. Del Gaudio, P. De Martino, G. Fornaro, S. Guarino, G. P. Ricciardi, E. SANSOSTI and P. LundGRen (2004b): The use of IFSAR and classical geodetic techniques for caldera unrest episodes: application to the Campi Flegrei uplift event of 2000, J. Volcanol. Geotherm. Res., 133, 247-260.

Langbein, J.O. (2003): Deformation of the Long Valley Caldera, California: inferences from measurements from 1988 to 2001, J. Volcanol. Geotherm. Res., 127 (3-4), 247-267.

Langbein, J.O., D.P. Hill, T.N. PARKer and S.K. WilkinSON (1993): An episode of re-inflation of the Long Valley caldera, eastern California, 1989-1991, J. Geophys. Res., 98, 15851-15870.

Langbein, J.O., D. Dzurisin, G. Marshall, R. Stein and J. RundLE (1995): Shallow and peripheral volcanic sources of inflation revealed by modeling two-color geodimeter and leveling data from Long Valley caldera, California, 1988-1992, J. Geophys. Res., 100, 12487-12495.

Lirer, L., G. LuONGo and R. Scandone (1987): On the Volcanological Evolution of Campi Flegrei, Eos, Trans. Am. Geophys. Un., 68, 226-234.

Lundgren, P., S. Usai, E. SAnsosti, R. LAnari, M. Tesauro, G. Fornaro and P. Berardino (2001): Modeling surface deformations observed with synthetic aperture radar interferometry at Campi Flegrei caldera, Geophys. Res. Lett., 106, 19,355-19,366.

Lundgren, P., F. Casu, M. Manzo, A. Pepe, P. Berardino, E. SANSOSTI and R. LANARI (2004): Gravity and magma induced spreading of Mt. Etna volcano revealed by satellite radar interferometry, Geophys. Res. Lett., 31, L04602, doi: 10.1029/2003GL018736.

Manzo, M., G.P. Ricciardi, F. Casu, G. Ventura, G. Zeni, S. Borgström, P. Berardino, C. Del Gaudio and R. LANARI (2006): Surface deformation analysis in the Ischia Island (Italy) based on spaceborne radar interferometry, J. Volcanol. Geotherm. Res., 151, 399-416.

Massonnet, D., M. Rossi, C. Carmona, F. Ardagna, G. Peltzer, K. Feigl and T. Rabaute (1993): The displacement field of the Landers earthquake mapped by radar interferometry, Nature, 364, 138-142.

Merle, O. and A. Borgia (1996): Scaled experiments of volcano spreading, J. Geophys. Res., 101, 13,805-13,817.

Monaco, C., P. TAPponnier, L. Tortorici and P.Y. Gillot (1997): Late Quaternary slip rates on the AcirealePiedimonte normal faults and tectonic origin of Mt. Etna (Sicily), Earth Planet. Sci. Lett., 147, 125-139.

Mora, O., J.J. Mallorquí and A. Broquetas (2003): Linear and nonlinear terrain deformation maps from a reduced set of interferometric SAR images, IEEE Trans. Geosci. Remote Sensing, 41, 2243-2253.

Neri, M., V. Acocella, B. Behncke, V. Maiolino, A. ORSINO and R. VELARDITA (2005): Contrasting triggering mechanisms of the 2001 and 2002-2003 eruptions of Mt. Etna (Italy), J. Volcanol. Geotherm. Res., 144, 235-255.

Neri, M., F. GugLielmino and D. Rust (2007): Flank instability on Mt. Etna: Radon, radar interferometry, and geodetic data from the southwestern boundary of the unstable sector, J. Geophys. Res., 112, B04410, doi: 10.1029/2006JB004756.

Newman, A.V., T.H. Dixon and N. Gourmelen (2006): A four-dimensional viscoelastic deformation model for Long Valley Caldera, California, between 1995 and 2000, J. Volcanol. Geotherm. Res., 150 (1-3), 244-269.

Orsi, G., M. D'Antonio, S. DE Vita and G. Gallo (1992): The Neapolitan Yellow Tuff, a large-magnitude trachytic phreatoplinian eruption: eruptive dynamics, magma withdrawal and caldera collapse, J. Volcanol. Geotherm. Res., 53, 275-287.

Orsi, G., L. Civetta, C. Del Gaudio, S. De Vita, M.A. Di Vito, R. Isaia, S. Petrazzuoli, G.P. Ricciardi and C. RICCO (1999): Short-Term Ground Deformations and Seismicity in the Nested Campi Flegrei Caldera (Italy): an example of active block resurgence in a densely populated area, J. Volcanol. Geotherm. Res., 91, 415-451.

OsSERVATORIO Vesuviano (2000): Crisi bradisismica della Caldera dei Campi Flegrei, Osservatorio Vesuviano Internal Report.

Peltzer, G. and P.A. Rosen (1995): Surface displacement 
of the 17 Eureka valley, California, earthquake observed by SAR interferometry, Science, 268, 13331336.

Pepe, A., E. Sansosti, P. Berardino and R. Lanari (2005): On the Generation of ERS/ENVISAT DinSAR TimeSeries via the SBAS technique, IEEE Geosci. Remote Sensing Lett., 2 (3), 265-269.

Romano, R. (1982): Succession of volcanic activity in the Etnean area, in Mt. Etna Volcano, a Review of Recent Earth Sciences Studies, edited by in R. Romano, Mem. Soc. Geol. It., 23, 27-48.

Romano, R. and C. Sturiale (1982). The Historial eruptions of Mt. Etna (Volcanological data), Mem. Soc. Geol. It., 23, 75-97.

Rosen, P.A., S. Hensley, I.R. Joughin, F.K. Li, S.N. MaDSEN, E. RodrigueZ and R. GoldSTEIn (2000): Synthetic Aperture Radar Interferometry, IEEE Proc., 88, 333376.

Rosen, P.A., S. Hensley, E. Gurrola, F. Rogez, S. Chan and J. MARTIN (2001): SRTM C-band topographic data quality assessment and calibration activities, in IGARSS'01 Proceedings, Sydney, Australia, July 2001, 739-741.

Rosi, M. and A. Sbrana (1987): Phlegrean Fields, Quad. Ricerca Scientifica, Roma, 114.

Rosi, M., L. Vezzoli, P. Aleotti and M. De Censi (1996): Interaction between caldera collapse and eruptive dynamics during the Campanian Ignimbrite eruption,
Phlegraean Fields, Italy, Earth Environ. Sci., 57, 7.

Scandone, R., F. Bellucci, L. LiRer and G. Rolandi (1991): The structure of the Campanian Plain and the activity of Neapolitan Volcanoes, J. Volcanol. Geotherm. Res., 48.

Sorey, M. L., V. S. Mc ConNell and E. Roeloffs (2003): Summary of recent research in Long Valley caldera, California, J. Volcanol. Geotherm. Res., 127 (3-4), 165-173.

TAnguy, J.C., M. Condomines and G. KiefFer (1997): Evolution of the Mt. Etna magma: constraints on the present feeding system and eruptive mechanism, J. Volcanol. Geotherm. Res., 75, 221-250.

Tizzani, P., P. Berardino, F. Casu, P. Euillades, M. ManZO, G. P. Ricciardi, G. ZENI and R. LANARI (2007): Surface deformation of Long Valley caldera and Mono Basin, California, investigated with the SBAS-InSAR approach, Remote Sensing Environ., doi: 10.1016/ j.rse.2006.11.015e.

UsAI, S. (2003): A least squares database approach for SAR interferometric data, IEEE Trans. Geosci. Remote Sensing, 41, 753-760.

Werner, C., U. Wegmuller, T. Strozzi and A. Wiesmann (2003): Interferometric point target analysis for deformation mapping, Proc. IGARSS '03, 7, 4362-4364.

ZebKer, H. A. and J. Villasenor (1992): Decorrelation in interferometric radar echoes, IEEE Trans. Geosci. Remote Sensing, 30, 950-959. 